\title{
Cross-Shift Peak Expiratory Flow Changes Are Unassociated With Respirable Coal Dust Exposure Among South African Coal Miners
}

\author{
Rajen N. Naidoo, MB.ChB, MPH, PhD, ${ }^{1 *}$ Thomas G. Robins, MD, MPH, ${ }^{2}$ \\ Margaret Becklake, MB.ChB, PhD, ${ }^{3}$ Noah Seixas, MS PhD, ${ }^{4}$ and Mary Lou Thompson, $\mathrm{PhD}^{5}$
}

\begin{abstract}
Background The objectives of this study were to determine whether cross-shift changes in peak expiratory flow rate (PEFR) were related to respirable dust exposure in South African coalminers.

Methods Fifty workers were randomly selected from a cohort of 684 miners from 3 bituminous coalmines in Mpumalanga, South Africa. Peak expiratory efforts were measured prior to the commencement of the shift, and at the end of the shift on at least two occasions separated by at least 2 weeks, with full shift personal dust sampling being conducted on each occasion for each participant. Interviews were conducted, work histories were obtained and cumulative exposure estimates were constructed. Regression models examined the associations of cross-shift changes in PEFR with current and cumulative exposure, controlling for shift, smoking and past history of tuberculosis.

Results There were marginal differences in cross-shift PEFR (ranging from 0.1 to $2 \mathrm{~L} / \mathrm{min}$ ). Linear regression analyses showed no association between cross-shift change in PEFR and current or cumulative exposure. The specific shift worked by participants in the study showed no effect.

Conclusions Our study showed no association between current respirable dust exposure and cross-shift changes in PEFR. There was a non-significant protective effect of cumulative dust exposure on the outcome, suggesting the presence of a "healthy worker survivor effect" in this data. Am. J. Ind. Med. 50:992-998, 2007. ๑ 2007 Wiley-Liss, Inc.
\end{abstract}

KEY WORDS: cross shift; peak flow; respirable dust; coal

\section{INTRODUCTION}

Studies of cross-shift lung function changes are commonly conducted in occupational epidemiology as a measure of the acute respiratory effects of exposure. These

${ }^{1}$ Centre for Occupational and Environmental Health, University of KwaZulu-Natal, Durban, South Africa

${ }^{2}$ Department of Environmental Health Sciences, University of Michigan, Ann Arbor, Michigan

${ }^{3}$ Department of Epidemiology, Biostatistics and Occupational Health, McGill University/ Montreal Respiratory Epidemiology and Clinical Research Unit, Montreal Chest Institute, Montreal, Quebec, Canada

${ }^{4}$ Department of Environmental Health, University of Washington, Seattle, Washington

${ }^{5}$ Biostatistics Unit, Medical Research Council, Durban, South Africa

Human Subjects Declaration: All participants in this study gave written informed consent, participated voluntarily, and had the right to withdraw at any stage. Ethical approval was obtained from the Institutional Review Board of the University of Michigan and the Ethics Committee of University of KwaZulu-Natal. studies have focussed on exposures likely to cause occupational asthma (for example, chemical, wood, food agents) [Meijer et al., 1998; Zuskin et al., 1998; ErkinjunttiPekkanen et al., 1999; Schlunssen et al., 2002, 2004] or exposure to bioaerosols and endotoxins (metalworking 
fluids, grain dust, cotton dust) [Kennedy et al., 1989; Fonn et al., 1993; Christiani et al., 1994; Robins et al., 1997; Draper et al., 2003; Beckett et al., 2005]. In addition, a number of longitudinal studies have demonstrated that acute reversible cross-shift changes in lung function are predictive of accelerated declines in lung function over a period of years with continuing exposure [Ware et al., 1990]. Similar investigations into acute responses from exposure to inorganic respirable dusts at work have been few.

By contrast, since the late 1980s several cohort studies have clearly shown that exposure to respirable dust is doserelated to irreversible decrements in lung function among British [Love, 1982] and United States [Attfield, 1985] coalminers, as well as in goldminers from South Africa [Oxman et al., 1993]. Two studies have examined the presence of airways hyperreactivity among coalminers [Hudgel and Roe, 1988; Petsonk et al., 1995]-the former found a higher prevalence of airway reactivity in nonsmoking underground miners, compared to age and sex matched non-mining controls ( $41 \%$ vs. $20 \%$, respectively), while the latter found a lower prevalence of airway hyperreactivity among those workers employed in dusty jobs compared to unexposed co-workers (12\% vs. $39 \%$, respectively) (smoking status unknown), while among nonsmokers, $26 \%$ of miners responded to methacholine, compared to $23 \%$ of non-miners. Overall, the evidence suggests that, among coalminers, respirable dust exposure is implicated in short term reversible changes in forced expiratory volume in one second $\left(\mathrm{FEV}_{1}\right)$ and forced expiratory flow rates $\left(\mathrm{FEF}_{25-75}\right)$, indicative of both large and small airway effects.

Only two studies were found which investigated crossshift changes in respiratory function among coalminers. One found small but significant cross-shift decreases in ventilatory capacity $\left[\mathrm{FEV}_{1}, \mathrm{FEF}_{25-75}\right.$, forced vital capacity (FVC) and peak flow] among 93 US coal miners, compared to increased capacity among 42 non-miners [Lapp et al., 1972]. The second study of 23 underground and 8 surface workers in Scotland found a small cross-shift increase in various lung function parameters among morning shift underground workers, and significant decreases among night shift underground workers. However, none of these showed a relationship of cross-shift changes to concomitant dust exposure [Love, 1983].

Whether cross-shift changes and the presence of airways hyperreactivity among coalminers early in their careers are predictive of accelerated irreversible changes in lung function (as seen with other organic dusts) has not been evaluated in a prospective study. Of interest are the findings by Seixas et al., [1992] and Henneberger and Attfield [1996] which have evaluated longitudinal data: coalminers experienced a steep dose response relationship between cumulative respirable dust exposure and lung function decrements during the first few years of work, with a flattening of the dose-response in later years of continuing exposure. These considerations led to our interest in evaluating cross-shift changes among South African coalminers.

The overall objectives of the present cross sectional study were to determine whether cross-shift changes in peak expiratory flow rate (PEFR) among South African coal miners were related to current and/or cumulative dust exposure (CDE).

\section{METHODS}

\section{Selection of the Mining Operations}

These have been described previously [Naidoo et al., 2005]. In brief, a sample of current and ex-Black coal miners from three bituminous mines in Mpumulanga province, South Africa, was selected for this study. All mines had similar coal rank, carbon content, and (low) quartz content. The mining operations selected were among those which agreed to participate in the research project and had (a) reliable historical environmental monitoring data (i.e., data obtained by acceptable techniques and by trained personnel, with recorded sampling procedures) and (b) were located in a specified geographic region to facilitate study access.

\section{Selection of the Study Sample}

The workers participating in this study were selected from 684 miners chosen for a study of respirable dust and respiratory health among the three selected coalmines. The selection of these 684 miners is described in greater detail elsewhere [Naidoo et al., 2005]. Briefly they were selected on the basis years of exposure at the coalface, backbye and surface at these mines, and all were of similar socioeconomic status. For this cross-shift study, 50 workers were randomly selected from each of the miner samples already selected at these three mines, based on their specific job descriptions, with oversampling of miners at the coalface compared to those on the surface. Among the miners sampled in each session, 30 were taken from high exposure areas (coal face), 15 from the backbye and the remainder from surface areas from each of the three participating mining operations. This sampling allocation was adopted to ensure that the variability of exposures in the high exposure areas was adequately estimated.

\section{Peak Expiratory Flow Rate Measurements}

Following demonstrations of a peak expiratory effort by a member of the research team, and practice blows by the 50 participants, each participant provided three peak expiratory efforts into a Wright Peak Flow Meter prior to the commencement of the shift, and again at the end of the shift. 
The maneuvers were performed in a relatively dust free environment - the change rooms on the surface of the mines. All pre-shift tests were done on arrival at work, but not on any specific day of the working week. In the majority of cases miners were studied on the day shift, with a small number on the afternoon shift and two on the night shift. The maneuvers were observed by a member of the research team, who was also responsible for manually recording the results. Participants at the first two mines performed this test on two occasions, and at the other mine, on three occasions, each test being separated by several weeks. Expiratory efforts were validated against formal spirometric tests conducted on study participants by a trained spirometric technician as part of the health assessments within the broader study of 684 miners. Although $\mathrm{FEV}_{1}$ is a more stable measure of lung function, because of the hours of work (either start or end of shift times) of the participating workers, it was logistically difficult to have a trained spirometric technician available to conduct such assessments. One study has shown that peak flow recordings are correlated with $\mathrm{FEV}_{1}$ in asthma and COPD [Patel et al., 1999].

\section{Health Interviews, Occupational Histories and Job Descriptions}

Standardized questionnaires were administered by trained interviewers to each participant. Items covered included demographics, respiratory symptoms; chest illnesses; detailed work histories (past and current employment); tobacco use and family history.

The National Institute for Occupational Safety and Health (NIOSH) Occupational History Questionnaire used in the US Coal Workers' X-ray Surveillance Program was modified to obtain details on lifetime occupational histories. This involved determining the job description, the seam and section worked, and the duration of work in that job, seam and section. Information abstracted from written work histories was available at the time of interview to help participant recall [Bourbonnais et al., 1988].

Respiratory symptoms and smoking histories were obtained by using a modified version of the questionnaire used in the Round 4 of the US National Surveillance of Coal workers' Pneumoconiosis (NSCWP). The latter is based on the British Medical Research Council Respiratory Questionnaire.

\section{Evaluation of Exposure}

This is described in greater detail elsewhere [Naidoo et al., 2006]. In brief, personal air sampling pumps (Mine Safety Appliances Company, Pittsburgh, PA) fitted with nylon cyclone pre-separators were used according to the NIOSH prescribed method 0600 [DHHS, 1994]. Each miner in this cross-shift study was asked to wear a sampler for a full shift, on the same day as the peak flow efforts were conducted. Multiple rounds of sampling were conducted on each mine (three at mine 3 and two at the other two mines), and each period was separated by a few weeks, providing a total of 286 dust samples for this study.

Although approximately 50 workers from each mine participated in each of three sampling cycles, and although it was intended that all of these workers should belong to the original cohort, this was not always possible because of the worker being absent, on leave or on a different shift from that being sampled. In such instances workers not part of the original cohort, but working in the particular job in the particular exposure zone, were used as replacements for the exposure sampling. Peak flow assessments were not conducted on these workers. This report presents data only on the 146 workers on whom both peak flow measurements and exposure assessments were conducted.

The calculation of CDEs, described in detail elsewhere [Naidoo et al., 2006], used data from the mining operations, together with all the dust data from this cross-shift study. Regression equations were used to estimate the historical levels of exposure at the face, backbye and surface for each mine, and these coefficients were used to determine cumulative exposure for each participant.

\section{Analysis}

The primary outcome measurement was the PEFR. The response variable used was the difference between the best post- and best pre-exposure PEFR at each session. Because poorly executed blows were likely to introduce substantial noise, the best blow in each session was considered to be a more robust estimate. Diurnal variation in peak flow was adjusted for by the introduction of a binary "shift worked" variable (day/afternoon or night) variable in the analysis. We hypothesized a priori that post-shift PEFR would be less than pre-shift PEFR and that the difference between the two flow rates would increase (become increasingly negative) with increased exposure.

The primary exposure variable for each participant was his same-day exposure, calculated as the measured time weighted average for the shift across which his PEFR was measured. A second exposure variable was the CDE, calculated over the lifetime of work in the different exposure zones of the mine. Potential confounders considered were age, height, a self reported history of tuberculosis and smoking status (ever or never smoker).

Univariate and bivariate analyses were conducted, including summaries of response by exposure quartiles to see if patterns were consistent with a linear dose-response. Exploratory running smoothed estimation of cross-shift change in PEFR as a function of current exposure was also evaluated. Linear regression models were fitted using generalized estimating equations with exchangeable 
correlation structure to accommodate repeated measurements on the same individual. Robust variance estimation allowed for misspecification of the autocorrelation. Models were adjusted for the effect of the potential confounders described above. Model diagnostic checking established that one observation of cross-shift change in PEFR was an outlier, and strongly influenced the estimation. Results are reported with and without inclusion of this observation. The level of significance for hypothesis testing was set at $P<0.05$. All analyses were carried out using Stata Version 9.1.

\section{RESULTS}

A total of 146 of the 150 miners selected from the three mines participated in this study. Non-participation was generally due to absence from the shift or leave at the time of the assessments. No worker refused to participate in the study. The number of participants in each cycle varied across each mine (Table I). Samples were generally taken during the morning shift $(\mathrm{n}=222)$, but additional samples were taken from the afternoon shift $(n=62)$, with only 2 taken on the night shift. Among these participants, none reported any doctor diagnosis of chronic bronchitis or asthma, although $6.1 \%$ reported symptoms of chronic cough and chronic phlegm production of greater than 3-month duration.

The results of the investigator sampling survey are presented elsewhere [Naidoo et al., 2006]. A total of 286 samples were obtained, 270 were analyzed. The remaining 16 samples were not analyzed because of pump failure or cross-shift flow rate variation exceeding $5 \%$. These samples constituted the full dataset of researcher-collected samples that was used for the determination of cumulative exposure. As expected, dust concentrations were substantially higher in face jobs (ranging from 0.91 to $1.90 \mathrm{mg} / \mathrm{m}^{3}$ across the mines), with intermediate concentrations at the backbye $(0.48$ $0.52 \mathrm{mg} / \mathrm{m}^{3}$ across the mines) and lowest concentrations were obtained on the surface in all three mines $(0.15-$ $0.31 \mathrm{mg} / \mathrm{m}^{3}$ across the mines). Geometric mean concentrations were very consistent for backbye and surface jobs between mines, while concentrations on face jobs were somewhat higher in Mine 3.

There were only marginal differences in mean crossshift PEFR (Table II), with a mean drop of $2 \mathrm{~L} / \mathrm{min}$ post-shift relative to pre-shift in the miners on day shift and of $0.1 \mathrm{~L} / \mathrm{min}$

TABLE I. Number of Miners Participating for Each Mine Per Monitoring Cycle

\begin{tabular}{lccc} 
& Mine 1 & Mine 2 & Mine 3 \\
\hline Cycle 1 & $\mathrm{ND}^{\mathrm{a}}$ & $\mathrm{ND}^{\mathrm{a}}$ & 36 \\
Cycle 2 & 49 & 41 & 35 \\
Cycle 3 & 47 & 39 & 39 \\
\hline
\end{tabular}

${ }^{\mathrm{a}}$ No peak flow recording was done.
TABLE II. Descriptive Data of Study Participants

\begin{tabular}{lc} 
& Mean (SD), \\
& $\mathbf{n}=\mathbf{1 4 6}$ \\
\hline Age (years) & $41.2(6.8)$ \\
Height $(\mathrm{cm})$ & $168.6(6.7)$ \\
Weight $(\mathrm{kg})$ & $70.2(11.6)$ \\
Years employed (years) & $16.9(8.8)$ \\
FVC $(\mathrm{L})$ & $4.2(0.8)$ \\
FEV1 (L/s) & $3.5(0.7)$ \\
Pre-shift PEFR (L/min) & \\
$\quad$ Morning shift & $519.5(82.8)$ \\
Afternoon shift & $475.9(89.1)$ \\
$\quad$ Night shift & $585.0(30.6)$ \\
Post-shift PEFR (L/min) & \\
$\quad$ Morning shift & $521.5(84.8)$ \\
$\quad$ Afternoon shift & $475.8(88.9)$ \\
$\quad$ Night shift & $576.7(33.0)$ \\
Mean cross-shift ${ }^{\text {P }}$ PEFR $(\mathrm{L} / \mathrm{min})$ & \\
$\quad$ Morning shift & 2.0 \\
Afternoon shift & -0.1 \\
Night shift & -8.3 \\
Mean time weighted average $(\mathrm{GM})\left(\mathrm{mg} / \mathrm{m}^{3}\right)(\mathrm{GSD})$ & $1.2(3.1)$ \\
\hline
\end{tabular}

${ }^{\mathrm{a}}$ Mean cross-shift PEFR $=$ post-shift PEFR - pre-shift PEFR.

in the afternoon shift. Only two workers were sampled in the night shift.

There were 146 subjects with at least one current exposure record, 141 subjects for whom cumulative exposure could be calculated, and 136 subjects with both. The regression analyses are based on $n=131$ miners, excluding those participants on whom covariate data was absent. The regression analyses also excluded the instances where the 16 dust samples were not analyzed.

Running smoothed estimation of the association between current exposure and cross-shift differences in PEFR is shown in Figure 1. Multivariable linear regression analyses using generalized estimating equations and robust variance estimators showed no significant association between cross-shift change in PEFR and current or cumulative exposure. A single influential outlier in crossshift change in PEFR was identified: an individual working in the backbye with a mean cross-shift PEFR difference of 124 $\mathrm{L} / \mathrm{min}$, following an exposure of $8 \mathrm{mg} / \mathrm{m}^{3}$. Although we have no reason to believe that this observation was false, it did impact the results (see Table III and Fig. 1). The relationships between current exposure and cumulative exposure with cross-shift PEFR were not statistically significant either in the model including or excluding the influential outlier, although the coefficient estimates were in the expected direction for the inclusive model (Table III, Fig. 1). The effect of shift worked was not significant (Table III). When excluding the influential outlier a significant association 
TABLE III. Regression Models for Cross-Shift ${ }^{\star}$ Differences (Post-Pre) in Mean PEFR (Based on Data on 131 Miners Whose Data Was Analyzed in the Regression Analysis)

\begin{tabular}{cc}
\multicolumn{2}{c}{ Cross-shift difference in maximum PEFR (L/min) } \\
\hline $\begin{array}{c}\text { Model including influential } \\
\text { outlier coefficient estimate } \\
\text { (95\% CI) }\end{array}$ & $\begin{array}{c}\text { Model excluding influential } \\
\text { outlier coefficient estimate } \\
\text { (95\% CI) }\end{array}$ \\
\hline$-6.29(-97.2 ; 84.6)$ & $-3.61(-93.5 ; 86.3)$ \\
$-0.99(-4.44 ; 2.44)$ & $0.55(-1.49 ; 2.61)$ \\
$-0.29(-0.76 ; 0.18)$ & $-0.31(-0.76 ; 0.15)$ \\
$0.027(-0.47 ; 0.52)$ & $-0.011(-0.49 ; 0.47)$ \\
$4.19(-28.7 ; 37.1)$ & $4.33(-28.6 ; 37.2)$ \\
$2.53(-4.68 ; 9.73)$ & $1.92(-5.02 ; 8.86)$ \\
$0.08(-0.02 ; 0.18)$ & $0.09(0.01 ; 0.19)$ \\
$7.99(-1.16 ; 17.15)$ & $10.0(1.78 ; 18.3)$ \\
\hline
\end{tabular}

${ }^{a}$ Day shift versus other shifts (afternoon and night shifts). *Definition as on Table II.

was seen for shift worked (Table III). Smoking status and reported history of tuberculosis were associated with a decrease in PEFR across the work-shift, but this could have been due to chance alone (95\% CI: -4.68 to 9.73 and -28.7 to 37.1 , respectively) (Table III).

The correlation between age and cumulative exposure was moderate $(r=0.4)$. Additional regression analyses conducted with cumulative exposure, omitting age, showed no substantial change in outcome-exposure relationships (not shown in tables).

\section{DISCUSSION}

To the authors' knowledge, this is the first study which has measured cross-shift PEFR changes among coalminers on whom personal respirable dust exposure was assessed across the same shift. The primary finding was that there was

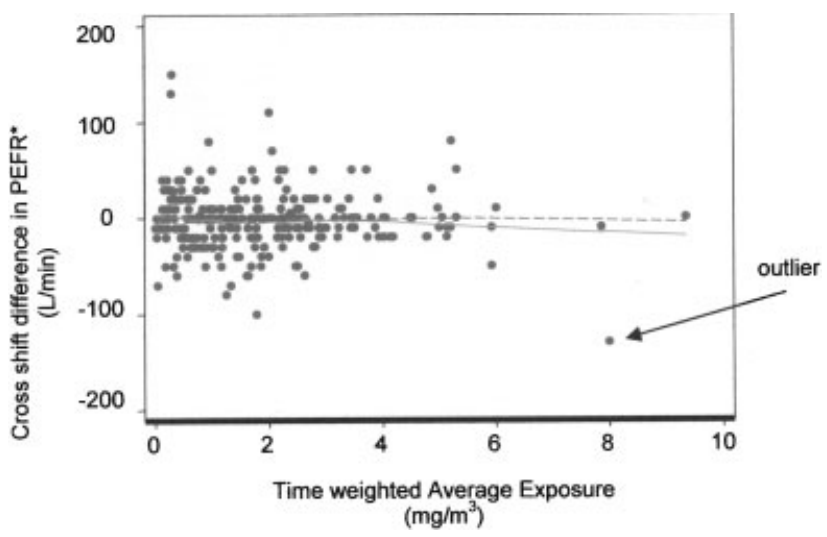

FIGURE 1. Non-parametric smoothed mean (unadjusted) cross-shift difference with (solid) and without (dashed) outlier ( ${ }^{*}$ cross-shift difference in PEFR $=$ post-shiftmaximum PEFR - pre-shiftmaximum PEFR). no association between respirable coalmine dust and postshift PEFR. This finding may have been affected by the lack of power within the study to detect what is presumably a small effect-if one does in fact exist.

The miners selected for this cross-shift study were part of a larger sample used to investigate respirable dust related lung function loss which were selected from three exposure zones (surface, backbye, and coalface), with oversampling in the higher exposure areas. This accounts for the higher CDE seen in this selection (Table II). The prevalence of doctor diagnosed diseases such as asthma and chronic bronchitis varied slightly between this sample and the cohort from which they were drawn. The prevalence of asthma was $0 \%$ and $2.5 \%$ in the study sample compared to the full cohort, and $0 \%$ and $0.3 \%$ for chronic bronchitis for sample and full cohort, respectively.

An interesting finding is the negative association between CDE and cross shift peakflow change. This finding is consistent with a "healthy worker survivor effect": that is, those able to "tolerate" higher CDE may represent a population resistant to adverse short-term effects of respirable dust, such as cross-shift changes. Other evidence of a healthy worker survivor effect has been reported in the full cohort [Naidoo et al., 2005]. A similar finding was reported by Petsonk et al. [1995].

Exposure related cross-shift declines in either $\mathrm{FEV}_{1}$ or PEFR have been documented with occupational allergens and exposure to either bioaerosols or endotoxins. The evidence of airway responses among workers exposed to inorganic dusts, particularly exposure to respirable dusts in coalmines, is probably on an inflammatory basis-possibly in response to the formation of a coal macule. It is unlikely that such a response could result within a working day crossshift drop in lung function. This certainly has not been borne out by our study. Other studies that have looked at cross-shift 
changes in workers exposed to inorganic dusts found varying results. In one of the only two previously reported studies, cross-shift $\mathrm{FEV}_{1}$ changes among underground coalminers varied across-shifts, with day shift workers showing a 1.8\% improvement compared to night workers having a 5.9\% decline [ $n=23$, Love, 1983]. According to the authors, this "shift" effect could not be explained by diurnal variation as these workers had been on these shifts for at least several weeks, allowing for circadian adjustment. The lack of personal dust measurements prevented a more detailed examination of exposure-outcome effect in this study. The other cross-shift study among coalminers $(n=93)$ found significant decreases in FVC and $\mathrm{FEV}_{1}$ across an 8-hr shift, but similar findings were not seen for peakflow-in keeping with the findings of our study [Lapp et al., 1972]. Peak flow may be a less sensitive outcome measure.

In conclusion, our study did not show any effect of current exposure on cross-shift declines in peak flow in South African coal miners. This may be due to several reasons, if indeed such an effect is present: inadequate sample size to detect a small change; dilution by diurnal variation across the morning and afternoon shift and the lack of sensitivity of the peakflow meter to detect a cross-shift respiratory function effect. The positive effect of cumulative exposure suggests a "healthy worker survivor effect", and this may act with the preceding factors to minimize the chance of detection of any exposure associated effect in this cross sectional study.

\section{ACKNOWLEDGMENTS}

This project was supported by grants from the Safety in Mines Research Advisory Committee (SIMRAC) of the Department of Minerals and Energy (Project No.: SIMHEALTH 607), South Africa, as well as part funding from the Rockefeller Foundation and the Medical Research Council of South Africa. The authors are grateful to the support given by Prof Mary Ross (SIMPROSS-SIMRAC), Professors Al Franzblau and Xihong Lin (University of Michigan, USA) and Professors Jinabhai and Lalloo (University of KwaZuluNatal). Our appreciation to Ingwe Coal Corporation, the National Union of Mineworkers and the staff and workers of the participating mining operations. Thanks to the research fieldworkers, Hlalanathi Ndhlovu, Tom Mashigo, Christine Mathebula, Christina Mabuza and administrator, Jenny Pillay and the staff of the Department of Public Health, University of KwaZulu-Natal.

\section{REFERENCES}

Attfield MD. 1985. Longitudinal decline in FEV1 in United States coal miners. Thorax 40:132-137.

Beckett W, Kallay M, Sood A, Zuo Z, Milton D. 2005. Hypersensitivity pneumonitis associated with environmental mycobacteria. Environ Health Perspect 113(6):767-770.
Bourbonnais R, Meyer F, Theriault G. 1988. Validity of self reported work history. Br J Ind Med 45:29-32.

Christiani DC, Ye TT, Wegman DH, Eisen EA, Dai HL, Lu PL. 1994. Cotton dust exposure, across-shift drop in FEV1, and five-year change in lung function. Am J Respir Crit Care Med 150(5 Pt 1):1250-1255.

Department of Health and Human Sciences (DHHS). 1994. NIOSH method for particulates not otherwise regulated, respirable, Method 0600. NIOSH manual of analytic methods (NMAM), 4th edition. DHHS (NIOSH) Publication 94-113.

Draper A, Cullinan P, Campbell C, Jones M, Newman Taylor A. 2003. Occupational asthma from fungicides fluazinam and chlorothalonil. Occup Environ Med 60(1):76-77.

Erkinjuntti-Pekkanen R, Slater T, Cheng S, Fishwick D, Bradshaw L, Kimbell-Dunn M, Dronfield L, Pearce N. 1999. Two year follow up of pulmonary function values among welders in New Zealand. Occup Environ Med 56(5):328-333.

Fonn S, Groeneveld HT, deBeer M, Becklake MR. 1993. Relationship of respiratory health status to grain dust in a Witwatersrand grain mill: Comparison of workers' exposure assessments with industrial hygiene survey findings. Am J Ind Med 24(4):401-411.

Henneberger PK, Attfield MD. 1996. Coal mine dust exposure and spirometry in experienced miners. Am J Respir Crit Care Med 153:1560-1566.

Hudgel D, Roe R. 1988. Nonspecific airway hyperreactivity in nonsmoking bituminous coal miners demonstrated by quantitative methacholine inhalational challenge. J Lab Clin Med 111:684-691.

Kennedy SM, Greaves IA, Kriebel D, Eisen EA, Smith TJ, Woskie SR 1989. Acute pulmonary responses among automobile workers exposed to aerosols of machining fluids. Am J Ind Med 15(6):627-641.

Lapp NL, Hankinson JL, Burgess DB, O’Brien R. 1972. Changes in ventilatory function in coal miners after a work shift. Arch Environ Health 24:204-208.

Love RG. 1983. Lung function studies before and after a work shift. Br J Ind Med 40:153-159.

Love RG, Miller BG. 1982. Longitudinal study of lung function in coalminers. Thorax 37:193-197.

Meijer E, Heederik D, Kromhout H. 1998. Pulmonary effects of inhaled dust and fumes: Exposure-response study in rubber workers. Am J Ind Med 33(1):16-23.

Naidoo RN, Robins TG, Seixas NS, Lalloo UG, Becklake M. 2005. Differential respirable dust related lung function effects between current and former South African coal miners. Int Arch Occup Environ Health 78:293-302.

Naidoo R, Seixas N, Robins TG. 2006. Respirable dust exposure in South African Coal Mines. J Occup Environ Hygiene 3:293-300.

Oxman AD, Muir DCF, Shannon HS, Stock SR, Hnidzo E, Lange HJ. 1993. Occupational dust exposure and chronic obstructive pulmonary disease- a systemic overview of the evidence. Am Rev Respir Dis $148: 38-48$

Patel MC, Mehta KB, Miler A. 1999. Peak flow in COPD: To define the relationship between $\mathrm{FEV}_{1}$ and $\mathrm{PF}$ in patients with COPD and compare it with that seen in asthma patients. Chest 116(4 Supplement 2):338S.

Petsonk EL, Daniloff EM, Mannino DM, Wang ML, Short SR, Wagner GR. 1995. Airway responsiveness and job selection: A study in coal miners and non-mining controls. Occup Environ Med 52:745-749.

Robins T, Seixas N, Franzblau A, Abrams L, Minick S, Burge H, Schork MA. 1997. Acute respiratory effects on workers exposed to metalworking fluid aerosols in an automotive transmission plant. Am J Ind Med 31(5):510-524. 
Schlunssen V, Schaumburg I, Taudorf E, Mikkelsen AB, Sigsgaard T. 2002. Respiratory symptoms and lung function among Danish woodworkers. J Occup Environ Med 44(1):82-98.

Schlunssen V, Schaumburg I, Heederik D, Taudorf E, Sigsgaard T. 2004. Indices of asthma among atopic and non-atopic woodworkers. Occup Environ Med 61(6):504-511.

Seixas NS, Robins TG, Attfield MD, Moulton LH. 1992. Exposure response relationships for coal mine dust and obstructive disease following enactment of the Federal Coal Mine Health and Safety Act of 1969. Am J Ind Med 21:715-734.

Ware J, Dockery D, Louis TA, Xu X, Ferris BG, Speizer FE. 1990. Longitudinal and cross-sectional estimates of pulmonary function decline in never-smoking adults. Am J Epidemiol 132:685-700.

Zuskin E, Kanceljak B, Schachter EN, Godnic-Cvar J, Mustajbegovic J, Budak A. 1998. Respiratory function and immunological status in cocoa and flour processing workers. Am J Ind Med 33(1):24-32. 